Jurnal Keperawatan Padjadjaran

ISSN 2338-5324 (print)

ISSN 2442-7276 (online)

Online di http://jkp.fkep.unpad.ac.id

DOI : $10.24198 / \mathrm{jkp}$

\title{
Demographic Factors and Disease History Associated with Dementia among Elderly in Nursing Homes
}

\author{
Lisna Anisa Fitriana ${ }^{1}$, Nazhifa Ufamy ${ }^{2}$, Kusnandar Anggadiredja ${ }^{2}$, Linda Amalia ${ }^{1}$, Setiawan \\ Setiawan $^{3}$, I Ketut Adnyana ${ }^{2}$ \\ ${ }^{1}$ Faculty of Sport Sciences and Health Education, Universitas Pendidikan Indonesia, Bandung, \\ Indonesia ${ }^{2}$ School of Pharmacy, Institut Teknologi Bandung, Bandung, Indonesia ${ }^{3}$ Faculty of \\ Medicine, Universitas Padjadjaran, Bandung, Indonesia \\ Corresponding email: lisna@upi.edu
}

Submitted: 10-05-2019 Accepted: 20-07-2020 Published: 01-08-2020

\begin{abstract}
Dementia is increasing in the world which is a major cause of disability and dependence in the elderly. This causes the elderly can not do their daily activities so often live in a nursing home. It is important to know the factors associated with dementia to prevent and treat dementia with appropriate interventions. The objective of this study was to identify the demographic factors and disease history associated with dementia among elderly in nursing homes. The research method was cross sectional study. Sample were recruited from three nursing homes located in Bandung and Garut using purposive sampling technique for a-3 month period $(n=163)$. Data were collected using questionnaire consisting of demographic data, disease history, and MMSE (Mini Mental State Examination). The analysis of data was performed using chi-square test, fisher test, and logistic regression analysis. In term of its association with dementia, low education had the higher odd ratio (OR: 5.90, 95\% CI: 2.02-17.20, $\mathrm{p}=0.001$ ) than unmarried status (OR: 4.78, 95\% CI: 1.23-18.52, $\mathrm{p}=0.024$ ) and stroke (OR: 0.23, 95\% CI: 0.06-0.88, $\mathrm{p}=0.032$ ). However, diabetes mellitus was identified as confounding variable (OR: $0.10,95 \% \mathrm{CI}: 0.01-1.01, \mathrm{p}=0.051)$. In conclusion, low education, unmarried status, stroke, and diabetes mellitus were predictor factors of dementia among elderly in nursing homes. It is recommended to include effective treatment could be in the form of health education about management of stroke and diabetes, physical activity, improvement of nutritional adequate, and social activities to prevent loneliness.
\end{abstract}

Keywords: Dementia, diabetes mellitus, education, marital status, stroke. 


\section{Introduction}

Dementia is a clinical symptom that is indicated by the degradation of cognitive function progressively that burdens an individual's daily activities (Duong, Patel, \& Chang, 2017). In 2015, there were around 46.8 million of people with dementia worldwide, which was predicted to increase up to 74.7 million in 2030 and 150 million in 2050 (Livingston et al., 2017; Baumgart et al., 2015). The estimated number of people with dementia in Indonesia in 2015 reached 1.2 million. That number is predicted to double by 2030, and to 4 million by 2050 (Kemenkes RI, 2016). This is related to higher life expectancy in people in developed countries, so that the elderly population and dementia people also increases.

Dementia globally is a health and social care problem that affects individuals, families and friends due to an increase in dependency, behavior change, and health financing (Livingston et al., 2017; Fitriana et al., 2019). In 2015 it was estimated that the cost for dementia management was USD 818 billion globally and was predicted to continue to increase along with the increase in dementia population(Livingston etal., 2017). Cognitive decline is one of the reasons for families to transfer the elderly to the institutional care in nursing homes, especially those with severe dementia, behavioral disorders, depression, and disturbances in carrying out daily activities (Dramé et al., 2012; Toot, Swinson, Devine, Challis, \& Orrell, 2017). However, a study demonstrated that dementia patients is found 19 times higher in nursing home than in the community (Hoffmann et al., 2014).

The association of Alzheimer's reports that diabetes, obesity, smoking, and hypertension can increase the risk of dementia (Baumgart et al., 2015). Other factors related to dementia are age, ethnicity, gender, genetic, physical activity, drugs, education, alcohol, comorbidities, and the environment (J. H. Chen, Lin, \& Chen, 2009). According to Perhimpunan Dokter Spesialis Saraf Indonesia (2016), risk factors of dementia involve unmodifiable risk (age, gender, genetic factors) and modifiable risk (hypertension, hypercholesterolemia, diabetic mellitus, stroke, diet, exercise, stress, heart disease, high homocysteine, and follicle acid deficiency).

A study in China involving 943 elderly in nursing homes revealed that the stroke history had risk 1.515 times becoming dementia (Xu et al., 2017). Meanwhile, a study in Taiwan show that increased dementia is found 1.42 times in the elderly with widowed or widowed status (Fan et al., 2015). Xu et al (2017) study show that age related to dementia among elderly in nursing homes (OR 1.029). The other study show that osteoarthritis had risk 1.25 times (Huang et al., 2015) and diabetes 1.18 times (Crane et al., 2013) becoming dementia. However, a study about disease history as modifiable risk of dementia in Indonesia is limited. The purpose of this study was to identify demographic factors and disease history associated with dementia among elderly in nursing homes.

\section{Method}

A cross-sectional study was conducted from January to March 2019. The subject of the study was taken using purposive sampling technique from three nursing homes: Budi Pertiwi Bandung, Senjarawi Bandung, and Rehabilitasi Lansia Garut, West Java. Nursing homes provide residential care for elderly also reffered to as old people's homes, care homes, or long-term facilities. The subjects involved in this study had fulfill the age criteria ( $>60$ years), good hearing and vision, and were willing to become subject of the study. In total, 176 subjects aged 60 years and older were initially enrolled in the study, of whom 13 subjects were excluded for the following reasons: refusal to partisipate, language problems, and severe auditory and visual deficits. The elderly subjects or their caregiver signed the informed consent before the study was conducted. The study was conducted at the Ethic Committee of Universitas Padjadjaran (No.1266/UN6. $\mathrm{KEP} / \mathrm{EC} / 2018$ ).

The instrument to collect the data was a questionnaire containing questions related to respondents' identity and anamnesis related to disease history according to the doctors or nurses. The dementia test used MMSE (Mini Mental State Examination) containing 
Lisna Anisa Fitriana: Demographic Factors and Disease History Associated with Dementia among Elderly

30 questions related to orientation, memory, language, registration, and attention, with the score $<24$ was set as criteria for dementia (Arevalo-Rodriguez et al., 2015). Data was collected by interviewing the elderly subjects and nursing home staffs, observing the ability to do daily activities, and physical assessment of the elderly subjects.

The elderly subjects were divided into two groups, dementia and non-dementia (including the MCI patient). Demographic data consists of age, sex, education, and marital status. Educational categorization divided the subjects into high and low levels of education. Low level education covered subjects who were education $\leq 9$ years or never receive formal education, elementary school level, and junior high school level). Meanwhile, the subjects with educational background of senior high school and higher were considered having high level education. Marital status classified the subjects into married and unmarried (never married, widowed, or divorced). Meanwhile, disease history consist of hypertension, heart disease, stroke, diabetes mellitus, rheumatic, osteoarthritis, and uric acid.

The data were analyzed using statistical program for social sciences (SPSS) version 25. The elderly subjects were divided into two categories: dementia and non dementia. Univariate tests using mean and standard deviation, frequency, and percentage. Test of Normality used Kolmogorov smirnov. Mannwhitney used to compare numerical data (MMSE, BMI (body mass index), sistole, diastole) and chi-square test or fisher exact test to compare categorical data (age, sex, education, marital status, disease history). Multivariate tests used logistic regression to determine the final model of variables related to dementia (Nuraeni, Mirwanti, Anna, \&
Nurhidayah, 2019). Multivariate analysis revealed the result of calibration test of Hosmer-Lameshow with the value $\mathrm{p}=0.772$. The Hosmer-Lameshow test to determine goodness of fit for logistic regression models. Differences were considered statistically significant for $p$ values of less than 0.05 .

\section{Results}

The research was conducted for three months from January to March 2019 on 176 elderlies in three nursing homes. On 163 elderlies who fulfilled the inclusion criteria consists of 110 elderlies gained the average score of MMSE was $12.78 \pm 9.23$ for dementia group and 53 elderlies gained the score was $26.85 \pm 2.01$ for non-dementia group $(\mathrm{p}<0.001)$. However, there were no significant comparison on body mass index, sistole, and diastole between dementia and non-dementia group (Table 1).

Most of the dementia elderly, 84 elderlies (69.4\%) were in the $\geq 70$ years age category; 81 elderlies $(71.1 \%)$ were female; 104 elderlies $(73.2 \%)$ had low education; 106 elderlies $(69.3 \%)$ were unmarried; and 57 elderlies $(64.8 \%)$ had hypertension history. Bivariate test showed that dementia was significantly related to education $(p<0.001)$. Dementia was also shown to significantly correlated with stroke $(\mathrm{p}=0.023)$ and diabetes mellitus ( $\mathrm{p}=0.007)$ (Table 2).

The logistic regression results showed that dementia was significantly related to low education (OR: 5.90, 95\% CI: 2.02-17.20, $\mathrm{p}=0.001$ ), marital status (OR: $4.78,95 \% \mathrm{CI}$ : $1.23-18.52, \mathrm{p}=0.024)$, stroke (OR: $0.23,95 \%$ CI: 0.06-0.88, $p=0.032$ ). However, diabetes mellitus was identified as confounding variable (OR: 0.10, 95\%CI:0.01-1.01, $\mathrm{p}=0.051)$ (Table 3).

Table 1 Characteristics of the elderly with and without dementia

\begin{tabular}{lccc}
\hline \multicolumn{1}{c}{ Variable } & Dementia (n=110) & Non-dementia (n=53) & p \\
\hline MMSE (score), mean (sd) & $12.78(9.23)$ & $26.85(2.01)$ & $<0.001^{*}$ \\
BMI (score), mean (sd) & $21.62(3.51)$ & $22.61(3.92)$ & 0.070 \\
Sistole (score), mean (sd) & $131.59(19.53)$ & $131.17(15.98)$ & 0.843 \\
Diastole (score), mean & $78.11(9.74)$ & $77.15(7.87)$ & 0.451 \\
(sd) & & & \\
\hline
\end{tabular}

${ }^{*} p<0.05 ; p$-value were derived from Mann-whitney test 
Lisna Anisa Fitriana: Demographic Factors and Disease History Associated with Dementia among Elderly

Table 2 Association of demographic profile and disease history with dementia

\begin{tabular}{|c|c|c|c|c|c|}
\hline Variable & $\begin{array}{c}\text { Dementia } \\
(\mathrm{n}=110)\end{array}$ & $\begin{array}{c}\text { Non-dementia } \\
(n=53)\end{array}$ & $\mathbf{p}$ & OR & $(95 \% \mathrm{CI})$ \\
\hline \multicolumn{6}{|c|}{ Age (years), n (\%) } \\
\hline $60-69$ & $26(61.9)$ & $16(38.1)$ & 0.370 & 0.72 & $0.34-1.49$ \\
\hline$\geq 70$ & $84(69.4)$ & $37(30.6)$ & & & \\
\hline \multicolumn{6}{|l|}{ Sex, n (\%) } \\
\hline Female & $81(71.1)$ & $33(28.9)$ & 0.138 & 1.69 & $0.4-1.49$ \\
\hline Male & $29(59.2)$ & $20(40.8)$ & & & \\
\hline \multicolumn{6}{|c|}{ Education, n (\%) } \\
\hline Low & $104(73.2)$ & $38(26.8)$ & $<0.001 *$ & 6.84 & $2.48-18.92$ \\
\hline High & $6(28.6)$ & $15(71.4)$ & & & \\
\hline \multicolumn{6}{|c|}{ Marital Status, n (\%) } \\
\hline Unmarried & $106(69.3)$ & $47(30.7)$ & 0.062 & 3.38 & $0.91-12.55$ \\
\hline Married & $4(40)$ & $6(60)$ & & & \\
\hline \multicolumn{6}{|l|}{ Hypertension } \\
\hline Yes & $57(64.8)$ & $31(35.2)$ & 0.423 & 0.77 & $0.39-1.48$ \\
\hline No & $53(70.7)$ & $22(29.3)$ & & & \\
\hline \multicolumn{6}{|l|}{ Heart disease } \\
\hline Yes & $4(66.7)$ & $2(33.3)$ & 0.636 & 0.96 & $0.17-5.43$ \\
\hline No & $106(67.5)$ & $51(32.5)$ & & & \\
\hline \multicolumn{6}{|l|}{ Stroke } \\
\hline Yes & $4(36.4)$ & $7(63.6)$ & $0.029 *$ & 0.25 & $0.007-0.89$ \\
\hline No & $106(69.7)$ & $46(30.3)$ & & & \\
\hline \multicolumn{6}{|c|}{ Diabetes mellitus } \\
\hline Yes & $1(16.7)$ & $5(83.3)$ & $0.014 *$ & 0.09 & $0.01-0.77$ \\
\hline No & $109(69.4)$ & $48(30.6)$ & & & \\
\hline \multicolumn{6}{|l|}{ Rheumatic } \\
\hline Yes & $19(82.6)$ & $4(17.4)$ & 0.095 & 2.56 & $0.82-7.94$ \\
\hline No & $91(65.0)$ & $49(35.0)$ & & & \\
\hline \multicolumn{6}{|l|}{ Osteoarthritis } \\
\hline Yes & $14(77.8)$ & $4(22.2)$ & 0.323 & 1.79 & $0.56-5.72$ \\
\hline No & $96(66.2)$ & $49(33.8)$ & & & \\
\hline \multicolumn{6}{|l|}{ Uric Acid } \\
\hline Yes & $3(50)$ & $3(50)$ & 0.301 & 0.47 & $0.09-2.40$ \\
\hline No & $107(68.2)$ & $50(31.8)$ & & & \\
\hline
\end{tabular}


Lisna Anisa Fitriana: Demographic Factors and Disease History Associated with Dementia among Elderly

Table 3 Final model factors associated with dementia

\begin{tabular}{|c|c|c|c|c|c|c|c|}
\hline Variable & B & S.E. & Wald & df & p & OR & $(95 \% \mathrm{CI})$ \\
\hline $\begin{array}{l}\text { Low } \\
\text { education }\end{array}$ & 1.78 & 0.55 & 10.56 & 1 & 0.001 & 5.90 & $2.02-17.20$ \\
\hline $\begin{array}{l}\text { Unmarried } \\
\text { status }\end{array}$ & 1.57 & 0.69 & 5.13 & 1 & 0.024 & 4.78 & $1.23-18.52$ \\
\hline Stroke & -1.48 & 0.69 & 4.58 & 1 & 0.032 & 0.23 & $0.06-0.88$ \\
\hline $\begin{array}{l}\text { Diabetes } \\
\text { mellitus }\end{array}$ & -2.27 & 1.16 & 3.81 & 1 & 0.051 & 0.10 & $0.01-1.01$ \\
\hline
\end{tabular}

\section{Discussion}

The results showed that demographic factor and disease history that associated with dementia among the elderly in nursing homes consists of low education $(\mathrm{p}=0.001)$, unmarried status $(\mathrm{p}=0.024)$, stroke $(\mathrm{p}=0.032)$, and diabetes mellitus $(\mathrm{p}=0.051)$. The study showed that the number of elderly subjects with dementia in the studied nursing homes was higher than those without dementia, and this had close correlation with the factors of age, sex, and education. A study in Europe involving 45,340 elderly demonstrated that the group of patients of $<75$ years old had dementia score of $1 \%$. This figure increased to $3.5 \%$ in the age group of $75-84$ years and $10.4 \%$ in the age group of $>84$ years (Ferreira, Brandão, \& Cardoso, 2018). Although our results did not show relation with age, this factor is considered one of the determining factors for dementia (Qiu \& Fratiglioni, 2018).

The higher percentage of female subjects in our study might be related to the longer life expectancy in female compared to male. In addition, the physiology of female individual is influenced by alteration of hormonal level. Thus, the decreased level of estradiol in menopause women compromises the protective function estrogen as an antitoxic agent that leads to neuronal death (Hestiantoro et al., 2019; Fitriana et al., 2019). Chêne et al (2015) study show that the risk of dementia in women is significantly higher than men after the age of 85 years. This finding is in line with a study in China show that sex not related with dementia (Xu et al., 2017). Chen et al (2016) study found that increased risk of dementia among older women associated with short sleep duration, that is $\leq 6$ hours/ night (HR 1.36).

The results further showed that the lower the education level elderly had 5.9 times the risk of becoming dementia. This finding is in line with a study conducted in China, involving 943 subjects, showing a correlation of high level of education with low risk of dementia (OR 0.587) (Xu et al., 2017). Another study has demonstrated that high level of education could prevent dementia by maintaining cognitive function (Lamotte et al., 2016). A systematic literature review revealed contradictory results with regard to correlation between education and dementia. In $58 \%$ of the reference significant correlations were shown while in the rest $42 \%$ of no correlation was found. The data suggested, however, relationship between education and dementia was consistent in developing compared to the developed regions (Sharp \& Gatz, 2011). Post mortem brain histology could further delineate the correlation between education level and dementia, as demonstrated by a study which showed that individuals with higher education had higher brain weight compared to those with lower education level. The study associated this finding with higher synaptodendritic development which eventually led to neurogenesis in individuals with higher education level (Brayne et al., 2010).

Marital and parental status were shown to play important role in the incidence of dementia as shown by a study result involving 354 dementia respondents that demonstrated widowed patients and those who had no children had higher risk of developing dementia (Sundström, Westerlund, MousaviNasab, Adolfsson, \& Nilsson, 2014). Different study recruiting 10,432 elderly that showed increased risk of dementia in individuals with 
widow or widowed status further corroborate the relation of marital status in dementia (Fan et al., 2015). The absence of partner was associated with stressful events leading to depression, and eventually lowered cognitive performance and dementia. Increased risk of dementia was also observed in unmarried subjects, especially in divorced and unmarried at all, aged 50 to 64 compared to those who were married.

Several hypotheses have been put forward on the protective effects of marriage against dementia. Marriage is associated with increase social support that could prevent anxiety and depression (Holwerda et al., 2014). An aspect related to marriage is sexual activity, and in this respect a study involving 6,833 subjects of 50 to 89 years of age found that subjects who were sexually active for one year showed lower risk of dementia (Wright \& Jenks, 2016).

In this study we found significant relationship between dementia and stroke $(p=0.032)$. This is because stroke can cause vascular dementia (Xu et al., 2017). In line with our data, the results of a prospective cohort study from 22 hospitals and 8 studies in the community with 7,511 subjects revealed a higher prevalence of pre-stroke dementia. Furthermore, an earlier study showed that $10 \%$ of patients had dementia before the first stroke, 10\% developed dementia soon after the first stroke, and one third of the subjects had dementia after multi strokes (Pendlebury \& Rothwell, 2009). Studies investigating stroke has certain characteristics which may increased risk of dementia such as the presence of multiple lesion, the volume of infarcts and the location of stroke (e.g. left hemisphere). According to pathogenic mechanisms process in brain a neurodegenerative process triggered by stroke by disrupting amyloid clearance or by activating autoimmune responses to brain antigens produced poststroke and its also related to accumulation of amyloid in arterial walls of cerebrovascular (Kuźma et al., 2018).

In this study we found the final model of factors that associated with dementia showed that diabetes mellitus is confounding variable $(p=0.051)$. This is because causative relationship between diabetes and cognitive decline in patient with dementia has not yet been clearly established. Inadequate cerebral circulation and recurrent hypoglycemic episodes in diabetic vascular diseases have been suggested to cause subclinical brain damage and permanent cognitive impairment (Li, Cesari, Liu, Dong, \& Vellas, 2017; Kurniawan \& Yudianto, 2016). Besides that, type 2 diabetes mellitus could cause cognitive impairment due to neurogenesis damage, vascular dysfunction, brain-blood barrier dysfunction, inflammation, hyperglycemia, and insulin resistance that lead ischemia and accelerates the pathology of Alzheimer's disease (Umegaki, 2014). The other study showed that diabetic patients were $60 \%$ higher at risk of developing dementia than those without diabetes, and women with diabetes had 19\% higher risk of developing vascular dementia than men (Chatterjee et al., 2016).

\section{Conclusion}

The results of the study showed that demographic factors and disease history that associated with dementia among elderly in nursing homes included low education, unmarried status, stroke, and diabetes mellitus. One of the consequence of these findings is that appropriate interventions are needed to prevent and treat dementia in the elderly staying in nursing homes. Health workers can prevent and slow the progression of dementia by providing health education about management of stroke and diabetes, physical activity, improvement of nutritional adequate, and social activities to prevent loneliness. Further studies can be conduct on the prevalence and risk factors of dementia with a greater number of respondent both in nursing homes and community in Indonesia.

\section{Acknowledgement}

We would like to express our gratitude to Institut Teknologi Bandung, Universitas Pendidikan Indonesia, and Universitas Padjadjaran for the funding of this study in "Program Penelitian Kolaborasi Indonesia $2019 "$ ". 
Lisna Anisa Fitriana: Demographic Factors and Disease History Associated with Dementia among Elderly

\section{References}

Arevalo-Rodriguez, I., Smailagic, N., Roquéi Figuls, M., Ciapponi, A., Sanchez-Perez, E., Giannakou, A., ... Cullum, S. (2015). Mini-Mental State Examination (MMSE) for the detection of Alzheimer's disease and other dementias in people with mild cognitive impairment (MCI). Cochrane Database of Systematic Reviews. https://doi. org/10.1002/14651858.CD010783.pub2

Baumgart, M., Snyder, H. M., Carrillo, M. C., Fazio, S., Kim, H., \& Johns, H. (2015). Summary of the evidence on modifiable risk factors for cognitive decline and dementia: A population-based perspective. Alzheimer's and Dementia. https://doi.org/10.1016/j. jalz.2015.05.016

Brayne, C., Ince, P. G., Keage, H. A. D., McKeith, I. G., Matthews, F. E., Polvikoski, T., \& Sulkava, R. (2010). Education, the brain and dementia: Neuroprotection or compensation? Brain. https://doi. org/10.1093/brain/awq185

Chatterjee, S., Peters, S. A. E., Woodward, M., Arango, S. M., Batty, G. D., Beckett, N., ... Huxley, R. R. (2016). Type 2diabetes as a risk factor for dementia in women compared with men: A pooled analysis of 2.3 million people comprising more than 100,000 cases of dementia. Diabetes Care. https://doi. org/10.2337/dc15-1588

Chen, J. C., Espeland, M. A., Brunner, R. L., Lovato, L. C., Wallace, R. B., Leng, X., ... Mysiw, W. J. (2016). Sleep duration, cognitive decline, and dementia risk in older women. Alzheimer's and Dementia. https:// doi.org/10.1016/j.jalz.2015.03.004

Chen, J. H., Lin, K. P., \& Chen, Y. C. (2009). Risk factors for dementia. Journal of the Formosan Medical Association. https://doi. org/10.1016/S0929-6646(09)60402-2

Chêne, G., Beiser, A., Au, R., Preis, S. R., Wolf, P. A., Dufouil, C., \& Seshadri, S. (2015). Gender and incidence of dementia in the Framingham Heart Study from mid-adult life. Alzheimer's and Dementia. https://doi. org/10.1016/j.jalz.2013.10.005

Crane, P. K., Walker, R., Hubbard, R. A., Li, G., Nathan, D. M., Zheng, H., ... Larson, E. B. (2013). Glucose levels and risk of dementia. New England Journal of Medicine. https://doi.org/10.1056/NEJMoa1215740

Dramé, M., Lang, P. O., Jolly, D., Narbey, D., Mahmoudi, R., Lanièce, I., ... Novella, J. L. (2012). Nursing home admission in elderly subjects with dementia: Predictive factors and future challenges. Journal of the American Medical Directors Association. https://doi.org/10.1016/j.jamda.2011.03.002

Duong, S., Patel, T., \& Chang, F. (2017). Dementia: What pharmacists need to know. Canadian Pharmacists Journal. https://doi. org/10.1177/1715163517690745

Fan, L. Y., Sun, Y., Lee, H. J., Yang, S. C., Chen, T. F., Lin, K. N., ... Chiu, M. J. (2015). Marital status, lifestyle and dementia: A nationwide survey in Taiwan. PLoS ONE. https://doi.org/10.1371/journal. pone. 0139154

Ferreira, R. G., Brandão, M. P., \& Cardoso, M. F. (2018). An update of the profile of older adults with dementia in Europe: findings from SHARE. Aging \& Mental Health, 1-8. https://doi.org/10.1080/13607863.2018.1531 385

Fitriana, L. A., Rohaedi, S., Sumartini, S., Amalia, L., \& Komariyah, L. (2019). Risk Factors of Dementia in Elderly at Nursing Home. Advances in Health Sciences Research. https://doi.org/10.2991/icsshpe-18.2019.48

Fitriana, L. A., Ufamy, N., Anggadiredja, K., Setiawan, S., \& Adnyana, I. K. (2019). Hubungan Tingkat Kemandirian (Basic dan Instrumental Activities of Daily Living) dengan Pendidikan, Status Marital, dan Demensia pada Lansia di Panti Wredha. (The relationshipbetween the level of independence (basic and instrumental activities of daily living) with education, marital status, and dementia in the elderly in nursing homes). Jurnal Pendidikan Keperawatan Indonesia. https://doi.org/10.17509/jpki.v5i2.21528 
Lisna Anisa Fitriana: Demographic Factors and Disease History Associated with Dementia among Elderly

Hestiantoro, A., Jasirwan, S. O., Wiwie, M., Shadrina, A., Ibrahim, N., \& Astuti, B. P. K. (2019). Low estradiol levels escalate menopausal symptoms leading to mild cognitive impairment in postmenopausal women. Medical Journal of Indonesia. https://doi.org/10.13181/mji.v28i1.2447.

Holwerda, T. J., Deeg, D. J. H., Beekman, A. T. F., van Tilburg, T. G., Stek, M. L., Jonker, C., \& Schoevers, R. A. (2014). Feelings of loneliness, but not social isolation, predict dementia onset: results from the Amsterdam Study of the Elderly (AMSTEL). Journal of Neurology, Neurosurgery \&amp;Amp; Psychiatry, 85(2), 135 LP - 142. https://doi. org/10.1136/jnnp-2012-302755

Huang, S. W., Wang, W. Te, Chou, L. C., Liao, C. De, Liou, T. H., \& Lin, H. W. (2015). Osteoarthritis increases the risk of dementia: A nationwide cohort study in Taiwan. Scientific Reports. https://doi.org/10.1038/ srep 10145

Kemenkes RI. (2016). Menkes: Lansia yang Sehat, Lansia yang Jauh dari Demensia. (Healthy elderly are those who are far from dementia). Retrieved January 12, 2019, from : https://www.depkes.go.id/

Kurniawan, T., \& Yudianto, K. (2016). Diabetes Self-Management and Its related Factors. Jurnal Keperawatan Padjadjaran. https://doi.org/10.24198/jkp.v4n3.6

Kuźma, E., Lourida, I., Moore, S. F., Levine, D. A., Ukoumunne, O. C., \& Llewellyn, D. J. (2018). Stroke and dementia risk: A systematic review and meta-analysis. Alzheimer's and Dementia. https://doi. org/10.1016/j.jalz.2018.06.3061

Lamotte, G., Morello, R., Lebasnier, A., Agostini, D., Bouvard, G., De La Sayette, V., \& Defer, G. L. (2016). Influence of education on cognitive performance and dopamine transporter binding in dementia with Lewy bodies. Clinical Neurology and Neurosurgery, 146, 138-143. https://doi.org/https://doi. org/10.1016/j.clineuro.2016.05.009

Li, J., Cesari, M., Liu, F., Dong, B., \& Vellas,
B. (2017). Effects of diabetes mellitus on cognitive decline in patients with Alzheimer disease: A systematic review. Canadian Journal ofDiabetes. https://doi.org/10.1016/j. jcjd.2016.07.003

Livingston, G., Sommerlad, A., Orgeta, V., Costafreda, S. G., Huntley, J., Ames, D., ... Mukadam, N. (2017). Dementia prevention, intervention, and care. The Lancet. https:// doi.org/10.1016/S0140-6736(17)31363-6

Nuraeni, A., Mirwanti, R., Anna, A., \& Nurhidayah, I. (2019). Determinant Factors of Depression in Patients with Coronary Heart Disease. Jurnal Keperawatan Padjadjaran. https://doi.org/10.24198/jkp.v7i3.1194

Pendlebury, S. T., \& Rothwell, P. M. (2009). Prevalence, incidence, and factors associated with pre-stroke and post-stroke dementia: a systematic review and meta-analysis. The Lancet Neurology. https://doi.org/10.1016/ S1474-4422(09)70236-4

Perhimpunan Dokter Spesialis Saraf Indonesia. (2016). Panduan Praktik Klinis Neurologi. (Neurology clinical practice guide). Retrieved January 4, 2019, from http:// snars.web.id/ppkneurologi/ppkneurologi.pdf

Qiu, C., \& Fratiglioni, L. (2018). Aging without Dementia is Achievable: Current Evidence from Epidemiological Research. Journal of Alzheimer's Disease. https://doi. org/10.3233/JAD-171037

Sharp, E. S., \& Gatz, M. (2011). Relationship between education and dementia: An updated systematic review. Alzheimer Disease and Associated Disorders. https://doi. org/10.1097/WAD.0b013e318211c83c

Sundström, A., Westerlund, O., MousaviNasab, H., Adolfsson, R., \& Nilsson, L. G. (2014). The relationship between marital and parental status and the risk of dementia. International Psychogeriatrics. https://doi. org/10.1017/S1041610213002652

Toot, S., Swinson, T., Devine, M., Challis, D., \& Orrell, M. (2017). Causes of nursing home placement for older people with dementia: 
Lisna Anisa Fitriana: Demographic Factors and Disease History Associated with Dementia among Elderly

A systematic review and meta-analysis. International Psychogeriatrics. https://doi. org/10.1017/S1041610216001654

Umegaki, H. (2014). Type 2 diabetes as a risk factor for cognitive impairment: Current insights. Clinical Interventions in Aging. https://doi.org/10.2147/CIA.S48926.

Wright, H., \& Jenks, R. A. (2016). Sex on the brain! Associations between sexual activity and cognitive function in older age. Age and Ageing. https://doi.org/10.1093/ageing/ afv197

Xu, S., Jin, X., Liu, C., Jin, Y., Xu, Y., Chen, L., ... Yan, J. (2017). Investigating the prevalence of dementia and its associated risk factors in a Chinese nursing home. Journal of Clinical Neurology (Korea). https://doi. org/10.3988/jen.2017.13.1.10 